\title{
Land Seismic Repeatability Prediction from Near Surface Investigation
}

\author{
Yousuf Al-Jabri* and Milovan Urosevic, Exploration Geophysics Department, Curtin University of Technology \\ and CO2CRC.
}

\begin{abstract}
Summary
High seismic repeatability is critical to the monitoring program of the Naylor Field because of the small timelapse effect related to $\mathrm{CO}_{2}$ injection into a depleted gas reservoir (Naylor). To understand the effect of changing ground conditions on repeatability, we conducted so-called "micro-array" investigation of the near-surface layers at this site. A feature of the injection test site area is the nearsurface karst topography. In such geological terrain, a change in water table level can influence the seismic response and cause changes in the seismic wave scattering pattern. Hence the aim of micro-array measurements was to determine the properties of the near surface layers during the wet and dry seasons. This could help us understand and ultimately predict the seismic response and hence survey repeatability at a given site. Measurements of seismic response due to near surface property changes (seasonal) could help optimise the design of time lapse surveys which ultimately yields improved survey differencing.

Measured elastic properties of the near surface are used to produce seismic response and predict repeatability as a function of the variable soil conditions. Comparison of numerical and field data is finally used to verify the validity of this approach. In this study we investigated the variation of elastic properties of both top soil and the deeper rugose clay-limestone interface as a function of water depth level. Such tests in fact simulate the measurements conducted in dry and wet seasons and help evaluate the effect of these seasonal variations on the seismic signature, which is then analysed in terms of non-repeatability. In this study, we use both micro-borehole (micro VSP) and micro-refraction arrays to analyse directional properties of the near-surface. Finally, numerical tests were performed with calibrated soil parameters.
\end{abstract}

\section{Introduction}

Time-lapse 3D or 4D seismic surveys are increasingly used to study and image changes in the seismic response induced by the production of hydrocarbons or the injection of $\mathrm{CO}_{2}$, water or steam into a reservoir. Such studies have often proved to be very effective. However, practically all of these studies have been conducted offshore. On land, unfortunately, time-lapse seismic changes are also produced by variations in the near-surface conditions, source signature variation, acquisition geometry (positioning and spacing), recording fidelity, processing methods, and of course ambient noise both natural and manmade. The residual differences in the repeated timelapse data that do not represent changes in the subsurface geology impact on the effectiveness of the time-lapse seismic methodology. It is widely accepted that time lapse repeatability of land seismic is low. It is however less understood which factors are critically important for time lapse land surveys. In the case of the Naylor $\mathrm{CO}_{2}$ injection test site area the presence of sinkholes and karst topography in the near surface zone make seismic non-repeatability investigations challenging but also interesting (Figure 1). In such geological terrane, the degree of signal scattering caused by a rugose limestone surface and caverns may depend on the depth of the water table. Consequently, repeated 2D seismic test lines have been acquired at Naylor location prior 3D baseline seismic acquisition and before $\mathrm{CO}_{2}$ injection commenced at this field. These seismic lines were recorded with a Mini-Vibroseis and Weight-Drop source in both wet and dry conditions. The aim of this work was to assess non-repeatability due to the source type change and variations in soil conditions (Urosevic et al., 2008). To help understand field observations we conducted different numerical simulations. Baker et al. (1997) and Jefferson et al. (1998) observed over periods of days to weeks that short-term moisture variations in near surface could have a significant impact on the quality and character of shallow seismic reflection data. However, analysing the changes in attenuation (absorption and scattering) and the propagation velocity of seismic energy in the upper $4 \mathrm{~m}$ of the near surface at the Naylor Field site is an important additional factor to be taking in to account when collecting seismic data for $4 \mathrm{D}$ analyses. The aim of this work was to analyse the effect of the variation in the water saturation in the first few meters of the near surface on the seismic signals and to understand the effects of variable near surface conditions on time-lapse seismic surveys. In particular we investigate the variation of elastic properties of both top soil and the deeper rugose clay-limestone interface as function of water depth level. Such tests in fact simulate the measurements conducted in dry and wet seasons and evaluate the contribution of these seasonal variations to seismic measurements in terms of nonrepeatability. This work will address the effect of the top soil conditions (saturation and hardness) on seismic signature and its repeatability.

\section{Methodology}

It is anticipated that for a given source, the nonrepeatability issues are, to the first order of approximation, related to variations of the properties of the top soil and underlying units. To analyse the effects of variable near surface conditions on time-lapse seismic surveys, we 


\section{D effects from seasonal water variation on the near surface properties}

performed refraction survey along three different direction, and reversed VSP and ultrasonic measurements (Figure 2). Due to the dimensions of these surveys we named them "micro-array" measurements. Together with these measurements we acquired core samples and measured Pwave velocity, amplitudes, absorption $(\mathrm{Q}$ and its proxy the peak frequency) during the wet and dry conditions of the near surface. The three refraction and reflection lines were $27 \mathrm{~m}$ long only. The orientation of the three seismic lines was at azimuth $30^{\circ}$ for line $\mathrm{A}, 90^{\circ}$ for line B and $150^{\circ}$ for line $\mathrm{C}$ which coincides with the maximum horizontal stress direction at depth. A total of 24 shot stations deployed along every refraction seismic line which utilised 24 geophones at $1 \mathrm{~m}$ spacing. The seismic source used for the refraction seismic surveys was a $4.5 \mathrm{~kg}$ Sledge Hammer and explosive charge (seismic detonator) for the reverse VSP. There were 5 shot positions of each line of the refraction lines (two from each end of the line with offset $1.5 \mathrm{~m}$ and $0.5 \mathrm{~m}$, and one in the middle of the line). For the reversed VSP (RVSP), we used the same borehole where we have extracted core samples. RVSP survey involved shots fired form depth of $1.9 \mathrm{~m}$ up to $0.2 \mathrm{~m}$ with $10 \mathrm{~cm}$ interval. 24 surface geophones were utilised at the surface to register borehole shots. Preserved core samples were measured as a function of soil saturation. These results were compared to RVSP and refection measurements. Finally, numerical tests were performed by using the calibrated soil parameters, logs data, cores and surface seismic measurements.

\section{Analysis and Results}

From refraction measurements we calculate horizontal Pwave velocities for the top $4 \mathrm{~m}$ of the near surface for three different azimuthal directions. Directional variations of the velocities and attenuation were calculated from refraction data. The Q-factor was calculated using the pulse rise timedomain method. The results of these calculations showed that the there is a consistence increase of the velocity and Q-factor with depth. Average directions variations are small (Figure 5). The RMS amplitude of the first arrival has been measured for the central receiver from six different shots at three different azimuthal directions around the borehole during the wet and dry conditions of the near surface. Figure 4 shows the change in amplitude due to a change in the water saturation during the wet and dry seasons. The average velocities were also measured from each shots of the micro array RVSP at every receiver location. The average velocity increases with depth, during wet season the average velocity is higher than velocity measured in dry season (Figure 3). Information from near surface measurements, RVSP, cores and surface seismic measurements were used then to construct the models of the near surface in dry and wet seasons (Figure 5). The simulated time-lapse seismic response for and dry near surface shows that the RMS amplitude difference is about $30 \%$ (Figure 6). These changes are purely caused by the seasonal changes in soil saturation and water table level.

\section{Conclusion}

The micro-array investigation of the near-surface layers at Naylor site indicated that the velocities and Q-factor show same directional pattern at this site. The top soil $(0.5 \mathrm{~m}$ thick agricultural layer or elasto-plastic zone) has a low velocity and low Q-factor hence affects both reflection amplitudes and arrival times. This zone significantly attenuates seismic energy. Micro-RVSP measurements show a consistence increase in velocity with depth and no seismic anisotropy. The change in the water saturation at near surface can cause the changes in velocity and attenuation. Around $30 \%$ of RMS amplitude difference could be measured at the reservoir level that originates from changes in the near surface conditions. Therefore, the residual differences in the repeated time-lapse data that do not represent changes in the subsurface geology impact on the effectiveness of the time-lapse seismic methodology. Numerical modelling results matches field data results. Therefore numerical modelling experiments built on near surface investigations could be used to predict seismic repeatability of time-lapse surveys at a given site.

\section{Acknowledgments}

This work is sponsored by CO2CRC and we thank S. Sharma and A. Kepic for making these experiments possible. We are grateful to our colleagues from Curtin University C. Dupuis and A. Dzunic for motivating discussions and help with data acquisition. Special thanks to Professor Brian Evens for providing useful comments and help in the editing process. We also thank Dr D. Sherlock for providing the "clif photo". 


\section{D effects from seasonal water variation on the near surface properties}

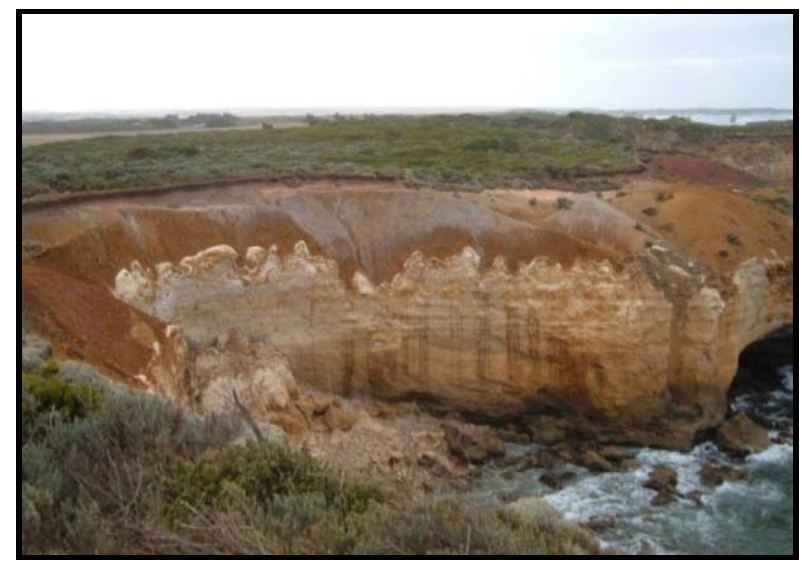

Figure 1: This "Cliff photo" was taken around $4 \mathrm{~km}$ from the site. The top layer is clay-rich zone, 3-5 $\mathrm{m}$ in thickness. Below it is the limestone.

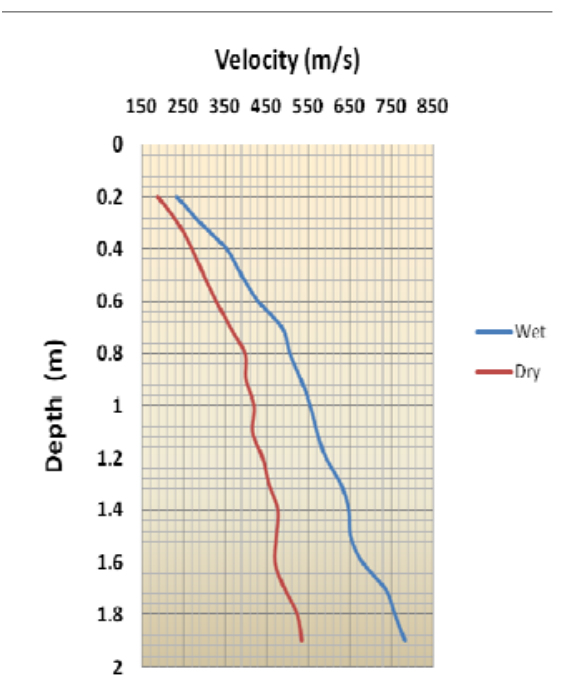

Figure 3: Average velocity profiles during dry and wet seasons as measured from reversed wake-away VSP.
Borehole placed at intersection of 2D seismic lines

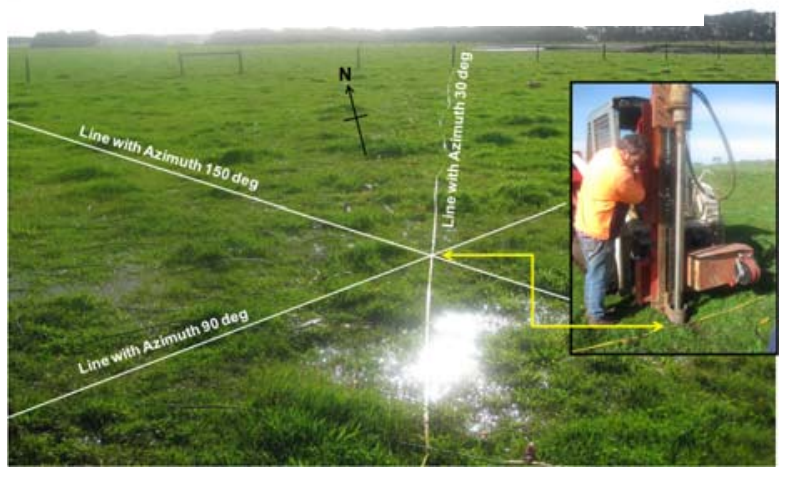

Figure 2: The geometry utilised for refraction and VSP surveys.

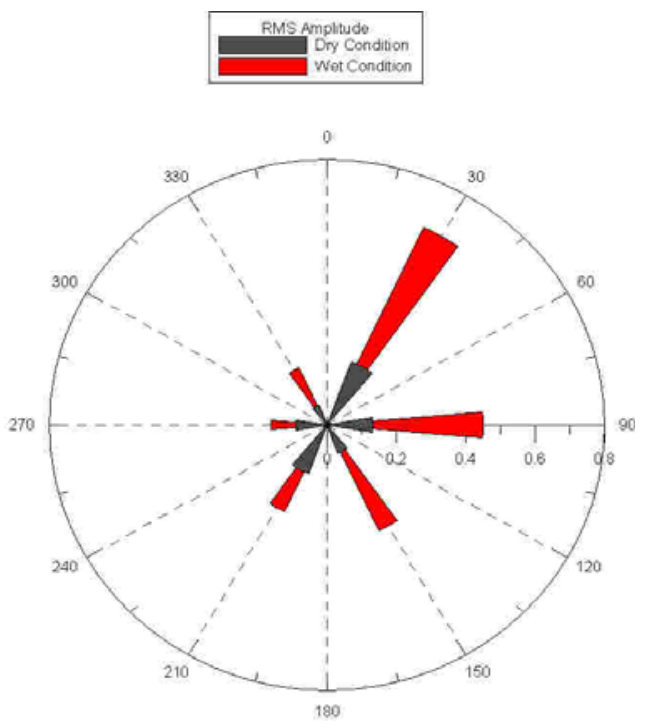

Figure 4: Measured RMS amplitude variations for the central-receiver from three different azimuthal directions for wet (in red) and dry (in grey) soil conditions. Certain directivity can be observed for the wet season. 


\section{D effects from seasonal water variation on the near surface properties}

\begin{tabular}{|c|c|c|c|c|c|}
\hline \multicolumn{2}{|c|}{ Wet Near Surface } & \multicolumn{2}{|l|}{ Dry Near Surface } & Stratigraphic Lithology & Thickne \\
\hline$V=405 \mathrm{~m} / \mathrm{s} \quad \rho=1787$ & $Q=14$ & $V=320 \mathrm{~m} / \mathrm{s} \quad \rho=1351$ & $Q=8$ & $\begin{array}{l}\text { Soil } \\
\text { sol }\end{array}$ & $0.5 \mathrm{~m}$ \\
\hline$V=814 \mathrm{~m} / \mathrm{s} \quad \rho=1981$ & $\mathrm{Q}=19$ & $V=615 \mathrm{~m} / \mathrm{s} \quad \rho=1609$ & $Q=13$ & Clay-1 & $1.0 \mathrm{~m}$ \\
\hline$V=1022 \mathrm{~m} / \mathrm{s} \quad \rho=2169$ & $\underbrace{Q=37}$ & $V=977 \mathrm{~m} / \mathrm{s} \quad \rho=1704$ & $Q=33$ & Clay-2 & $2.6 \mathrm{~m}$ \\
\hline$V=1791 \mathrm{~m} / \mathrm{s} \quad \rho=2430$ & $Q=54$ & $V=1791 \mathrm{~m} / \mathrm{s} \rho$ & $Q=54$ & tone & $117.8 \mathrm{~m}$ \\
\hline$V=2289 \mathrm{~m} / \mathrm{s} \quad \rho=2500$ & $Q=80$ & $V=2289 \mathrm{~m} / \mathrm{s} \quad \rho=2500$ & $Q=80$ & Gellibrand Marl & $335 \mathrm{~m}$ \\
\hline$V=2750 \mathrm{~m} / \mathrm{s} \quad \rho=2700$ & $Q=100$ & $V=2750 \mathrm{~m} / \mathrm{s} \quad \rho=2700$ & $Q=100$ & Clifton Formation & $17 \mathrm{~m}$ \\
\hline$V=2375 \mathrm{~m} / \mathrm{s} \quad \rho=2590$ & $Q=120$ & $V=2375 \mathrm{~m} / \mathrm{s} \quad \rho=2590$ & $Q=120$ & Nnarrawartuk Marl & $76.5 \mathrm{~m}$ \\
\hline$V=2895 \mathrm{~m} / \mathrm{s} \quad \rho=2200$ & $Q=130$ & $V=2895 \mathrm{~m} / \mathrm{s} \quad \rho=2200$ & $Q=130$ & Mepunga Formation & $118.5 \mathrm{~m}$ \\
\hline$V=2360 \mathrm{~m} / \mathrm{s} \quad \rho=2100$ & $Q=140$ & $V=2360 \mathrm{~m} / \mathrm{s} \quad \rho=2100$ & $Q=140$ & Dilwyn Formation & $209 \mathrm{~m}$ \\
\hline$V=3050 \mathrm{~m} / \mathrm{s} \quad \rho=2300$ & $Q=150$ & $V=3050 \mathrm{~m} / \mathrm{s} \quad \rho=2300$ & $Q=150$ & Pember Mudstone & $60.5 \mathrm{~m}$ \\
\hline$V=3185 \mathrm{~m} / \mathrm{s} \quad \rho=2230$ & $Q=160$ & $V=3185 \mathrm{~m} / \mathrm{s} \quad \rho=2230$ & $Q=160$ & Pebble Point Formation & $58.5 \mathrm{~m}$ \\
\hline$V=3350 \mathrm{~m} / \mathrm{s} \quad \rho=2380$ & $Q=170$ & $V=3350 \mathrm{~m} / \mathrm{s} \quad \rho=2380$ & $Q=170$ & Massacre Shale & $27 \mathrm{~m}$ \\
\hline$V=3105 \mathrm{~m} / \mathrm{s} \quad \rho=2280$ & $Q=180$ & $V=3105 \mathrm{~m} / \mathrm{s} \quad \rho=2280$ & $Q=180$ & Timboon Sandstone & $105.5 \mathrm{~m}$ \\
\hline$V=2795 \mathrm{~m} / \mathrm{s} \quad \rho=2350$ & $Q=200$ & $V=2795 \mathrm{~m} / \mathrm{s} \quad \rho=2350$ & $Q=200$ & Paaratte Formation & $398 \mathrm{~m}$ \\
\hline$V=3180 \mathrm{~m} / \mathrm{s} \quad \rho=2410$ & $Q=210$ & $V=3180 \mathrm{~m} / \mathrm{s} \quad \rho=2410$ & $Q=210$ & Skull Creek Formation & $205.5 \mathrm{~m}$ \\
\hline$V=3385 \mathrm{~m} / \mathrm{s} \quad \rho=2470$ & $Q=220$ & $V=3385 \mathrm{~m} / \mathrm{s} \quad \rho=2470$ & $\mathrm{Q}=220$ & Belfast Mudstone & $289.5 \mathrm{~m}$ \\
\hline$V=3888 \mathrm{~m} / \mathrm{s} \quad \rho=2500$ & $Q=230$ & $V=3888 \mathrm{~m} / \mathrm{s} \quad \rho=2500$ & $Q=230$ & Flaxmans Formation & $30 \mathrm{~m}$ \\
\hline$V=3748 \mathrm{~m} / \mathrm{s} \quad \rho=2340$ & $Q=240$ & $V=3748 \mathrm{~m} / \mathrm{s} \quad \rho=2340$ & $Q=240$ & Waarre C Formation & $30.5 \mathrm{~m}$ \\
\hline$V=3870 \mathrm{~m} / \mathrm{s} \quad \rho=2550$ & $Q=250$ & $V=3870 \mathrm{~m} / \mathrm{s} \quad \rho=2550$ & $Q=250$ & Waarre B Formation & $17 \mathrm{~m}$ \\
\hline$V=3550 \mathrm{~m} / \mathrm{s} \quad \rho=2370$ & $Q=260$ & $V=3550 \mathrm{~m} / \mathrm{s} \quad \rho=2370$ & $Q=260$ & Waarre A Formation & $39 \mathrm{~m}$ \\
\hline$V=4130 \mathrm{~m} / \mathrm{s} \quad \rho=2480$ & $Q=270$ & $V=4130 \mathrm{~m} / \mathrm{s} \quad \rho=2480$ & $Q=270$ & Eumeralla F & \\
\hline
\end{tabular}

Figure 5: Schematic geological profile for the Naylor site. Elastic parameters changes are introduced for the first three nearsurface layers.

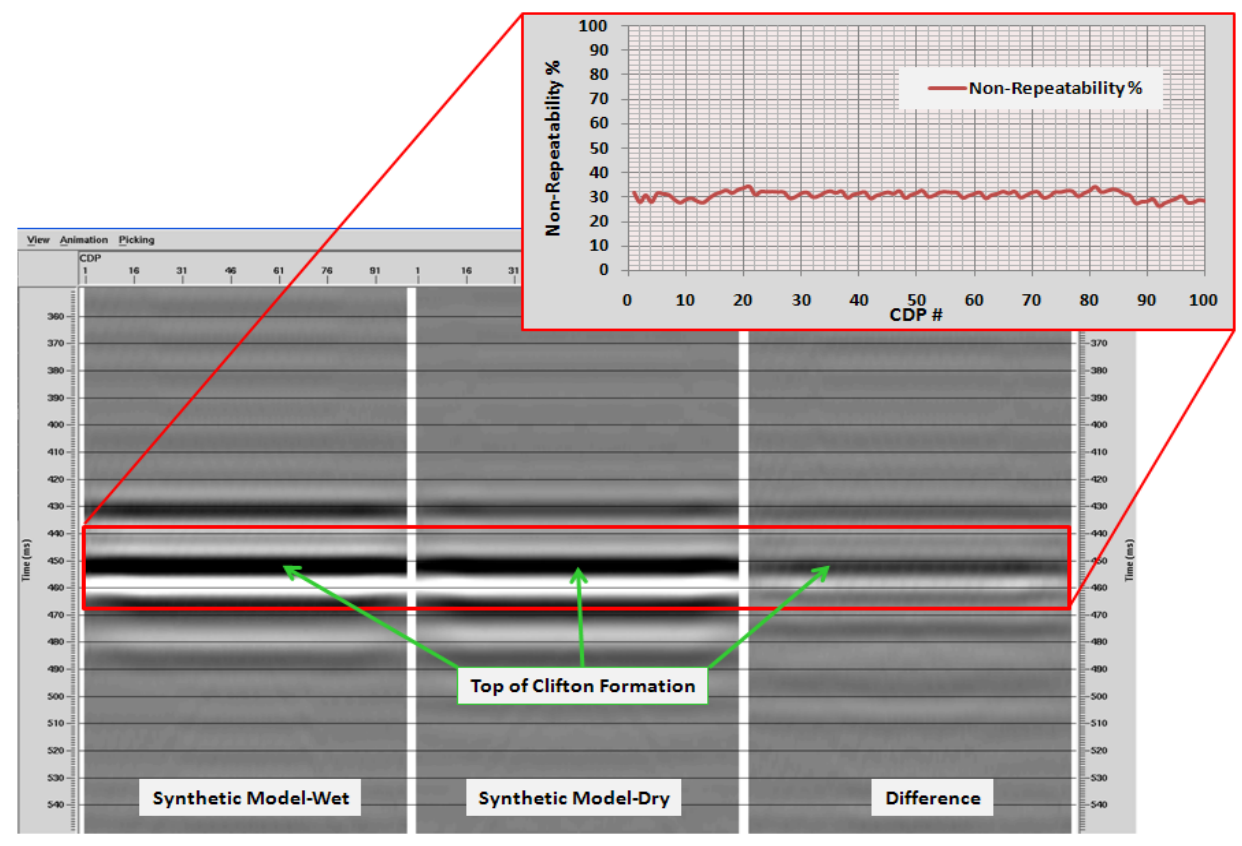

Figure 6: Synthetic seismograms for dry (left), wet (middle) near-surface conditions and their differences (right). A nonrepeatability curve computed for wet and dry cases using window of $40 \mathrm{~ms}$ around the Clifton Formation is shown at the top. 


\section{EDITED REFERENCES}

Note: This reference list is a copy-edited version of the reference list submitted by the author. Reference lists for the 2010 SEG Technical Program Expanded Abstracts have been copy edited so that references provided with the online metadata for each paper will achieve a high degree of linking to cited sources that appear on the Web.

\section{REFERENCES}

Al-Jabri, Y., M. Urosevic, and A. Kepic, 2008, The effects of the near-surface weathered zone on the CO2time-lapse monitoring program at Naylor-1, CO2CRC Otway Project, Victoria, Australia: CO2CRC Symposium.

Baker, G.S., Steeples, D.W. and Feroci, M., 1997, The time dependence of shallow reflection data: Leading Edge, 16, 1663-1666.

Blair, D. P., and A. T. Spathis, 1982, Attenuation of explosion-generated pulse in rock masses: Journal of Geophysical Research, 87, B5, 3885-3892, doi:10.1029/JB087iB05p03885.

Jefferson, R. D., D. W. Steeples, R. A. Black, and T. Carr, 1998, Effects of soil-moisture content on shallow-seismic data: Geophysics, 63, 1357-1362.

Urosevic, M., D. Sherlock, A. Kepic, S. Nakanishi, and S. Tcherkashnev, K., 2008, Time lapse VSP program for Otway basin CO2 sequestration pilot project, 70th Conference \& Exhibition, EAGE. 